\title{
Hong Kong healthcare workers' coronavirus disease 2019 (COVID-19) concerns: infection control, recognition and staff wellbeing, duty arrangements
}

\author{
Alastair P. Mah ${ }^{1,2,3}$, Kelvin C. Tong ${ }^{4}$, Linda L. Chan ${ }^{4}$, Peter D. Hibbert ${ }^{5,6}$, Fei-Chau Pang ${ }^{3}$ \\ ${ }^{1}$ Medical Affairs Office, United Family Healthcare, Beijing, China; ${ }^{2}$ Faculty of Health, School of Medicine, Deakin University, Geelong, Australia; \\ ${ }^{3}$ Faculty of Medicine, The Chinese University of Hong Kong, Hong Kong, China; ${ }^{4}$ Human Resources Division, Hospital Authority, Hong Kong, \\ China; ${ }^{5}$ Australian Institute of Health Innovation, Faculty of Medicine, Health and Human Sciences, Macquarie University, Sydney, Australia; \\ ${ }^{6}$ Australian Centre for Precision Health, University of South Australia Cancer Research Institute (UniSA CRI), School of Health Sciences, University \\ of South Australia, Adelaide, Australia \\ Contributions: (I) Conception and design: AP Mah, FC Pang; (II) Administrative support: KC Tong; (III) Provision of study materials or patients: AP \\ Mah, LL Chan, FC Pang; (IV) Collection and assembly of data: AP Mah, KC Tong, LL Chan, FC Pang; (V) Data analysis and interpretation: All \\ authors; (VI) Manuscript writing: All authors; (VII) Final approval of manuscript: All authors. \\ Correspondence to: Alastair P. Mah. B7, Universal Business Park, 10 Jiuxianqiao Road, Chaoyang District, Beijing 100015, China. \\ Email: alastair.mah@ufh.com.cn.
}

\begin{abstract}
Background: Appropriate human resources interventions to address healthcare workers' concerns are key to maintaining confidence and morale of staff to combat a pandemic in any healthcare system. The objectives of this study are to analyze concerns of healthcare workers in public hospitals during the initial 3 months, throughout which the Hong Kong Hospital Authority implemented multiple measures to address staff needs. Methods: A retrospective study analyzing the immediate and longitudinal concerns of healthcare workers during the coronavirus disease 2019 (COVID-19) pandemic. All enquiries by unsolicited phone calls and WhatsApp messages raised over a 12-week period from 29/1/2020 to 22/4/2020 were reviewed and categorized. Thematic analysis of the enquiries was conducted, together with timing and frequency of enquiry categories.

Results: A total of 1,868 enquiries were raised over the 12 -week period. These enquiries comprised $740(40 \%)$ in "recognition and staff wellbeing", 573 (31\%) in "infection control", 357 (19\%) in "duty arrangement" and the remaining 196 (10\%) "others".

Conclusions: Spikes spread over the 12 weeks of data capture demonstrated major concern areas for a healthcare system in maintaining the morale and confidence of staff. Financial incentives introduced during the pandemic may have drawbacks around equity, defining thresholds for payments and setting precedence. A Human Resources App and e-bulletins were effective in rapidly communicating information to staff and allaying their fears, especially during the initial phase of the crisis. Further study of financial incentives to help decision-makers understand the impact and consequences of such approaches should be undertaken.
\end{abstract}

Keywords: Coronavirus disease 2019 (COVID-19); health care workers; human resource; staff wellbeing

Received: 26 October 2020; Accepted: 09 March 2021; Published: 25 December 2021.

doi: $10.21037 /$ jhmhp-20-142

View this article at: http://dx.doi.org/10.21037/jhmhp-20-142

$\wedge$ ORCID: 0000-0003-1094-0365. 


\section{Introduction}

The World Health Organization classified coronavirus disease 2019 (COVID-19) as a pandemic on 11 March 2020. SARS-CoV-2, the coronavirus causing COVID-19, is highly infectious, with the number of global confirmed cases doubling from 118,319 to 266,073 in 10 days from 11 March to 21 March (1). The Hong Kong Special Administrative Region (HKSAR) Government adopted a containment strategy to isolate confirmed cases in hospitals and identify and quarantine close contacts and high-risk people such as overseas travelers (2). In order to achieve effective surveillance of COVID-19 infection by early diagnosis, the government conducted reverse transcription polymerase chain reaction (RT-PCR) COVID-19 tests extensively with a goal to have early diagnosis and isolation to prevent spreading of the coronavirus in the community. Following the experience of managing the severe acute respiratory syndrome (SARS) outbreak in 2003, the Hospital Authority (HA), which looks after all 43 public hospitals and institutions in Hong Kong, was funded to build 1,400 isolation beds so that public hospitals had dedicated facilities to contain both suspected and confirmed cases for the initial phase of any epidemic. Suspected cases, as defined by the Department of Health, are isolated in these beds with negative pressure facilities until their test results become available. The Department of Health also issues isolation orders to those confirmed infected patients and admit them to hospitals under HA for treatment until two consecutive COVID-19 tests, at least 24 hours apart, were negative (3).

In this initial phase in January 2020, many healthcare workers (HCW) faced significant fear and concerns about working in hospitals as they were uncertain about the characteristics of COVID-19. Previous studies have showed that $28 \%$ of professionals felt it was professionally acceptable to abandon work in favour of protecting themselves and their families (4). Hospital staff who decide to continue working often experience anxiety when they come to care for patients every day, by putting themselves in what are vulnerable and at-risk positions, as well as concerns about infecting family members in their household (4-6). It is known that during times of infectious catastrophic disasters such as SARS, the willingness of staff to report for duty can be low even if they have the ability to do so (7), and up to $50 \%$ of HCW surveyed said that they would not be willing to work during an influenza pandemic (8). In order to maintain a sufficient workforce to manage the influx of COVID-19 patients and ensure staff have sufficient capacity to adhere to infection control measures, HA hospitals cancelled more than $40 \%$ of elective services, including elective surgeries and endoscopy appointments, while maintaining essential services like cancer treatment and emergency care.

Unlike SARS, $80 \%$ of COVID-19 patients experience only mild or even no symptoms albeit having a high viral load at diagnosis (9). These findings raised apprehension amongst staff who work in hospitals that do not admit patients with suspected symptoms. HCWs who work in low-risk wards in hospitals that manage COVID-19 patients also voiced strong concerns about treating patients in general wards for non-infectious disease related medical care. HCWs would demand the same standard of personal protective equipment (PPE) used in high-risk areas, regardless of where they worked in the hospitals. Since aerosol generating procedures like intubation and bronchoscopy could create an environment whereby the coronavirus spreads like an air-borne disease, this led to additional PPE concerns for HCWs who are required to perform such tasks.

Despite implementing border controls, there had been community transmission with a number of patients whom the sources of infection could not be identified (10). During the early days of the epidemic, experts predicted that the social distancing measures will be enforced for another few months, as the virus would not be eliminated in the near future due to the infectivity of asymptomatic patients in the community (11), compounded by an increase in imported cases when border controls are gradually relaxed. The experience in Italy showed that up to $12 \%$ of COVID-19 patients would require intensive care unit admission (12), which could be a challenge for the capacity of hospitals in sustainably providing care for sporadic community outbreaks and maintaining the willingness of HCW to work in highrisk areas, as the longer-term management of this epidemic may require more than the need for self-actualisation of healthcare professionals (13). We present the following article in accordance with the MDAR reporting checklist and STROBE reporting checklist (available at http://dx.doi. org/10.21037/jhmhp-20-142).

\section{Measures taken by the organisation}

When Hong Kong confirmed its first case of COVID-19 in late January, HA activated its "emergency" response in all hospitals. The HA Central Command Committee was 
Table 1 Measures taken by the Hospital Authority from 23 Jan to $22 \mathrm{Apr}$

Infection control
PPE standard and utilization guidelines
PPE stockpile info
Revised admission criteria for isolation facilities
$2^{\text {nd }}$ tier temporary isolation ward
Designated coronavirus disease 2019 (COVID-19) community
clinics

Free COVID-19 test for staff and their family members

Temporary suspension of non-urgent medical services

Duty arrangement

Locum employment for manpower support

Work from home arrangements

Duty arrangement for staff with travel history

Defined high risk areas, deployment priority and exemption criteria

Recognition and staff wellbeing

Extra day off arrangement for eligible staff

Special rental allowance

Special emergency response allowance

Special honorarium scheme for crisis management

Free accommodation for eligible staff

General human resource (HR) supports (e.g., increased psychological support service, dedicated enquiry hotline, COVID-19 e-bulletin and designated COVID-19 webpage on HR app, etc.)

formed to lead and coordinate responses to the epidemic, and additional measures were introduced as additional funding became available in line with the anti-epidemic strategy led by the government. Based on available information from Wuhan, the response plan included the ramping up of infection control measures, changes in duty arrangements that are established in human resource (HR) policies, and providing recognition and support for staff well-being (Table 1).

\section{Dedicated botline}

A HR mobile application (the App) was developed in 2018, and over $90 \%$ of full-time staff had downloaded the App to retrieve personal information related to employment. With signs of an epidemic becoming evident in mainland China, a specific COVID-19 website was setup in mid-January 2020 to provide information to staff, which was accessible through this application.

In view of the confirmation of the first imported case in Hong Kong on 22 January, 2020, the COVID-19 e-bulletin was created, with the first edition pushed out to staff via the App on 23 January. A hotline was also set up for all staff and commenced on 29 January, 2020. This 24 -hour hotline was set up to solicit and address HCW concerns, be it queries about unknown treatment or apprehension about the effectiveness of measures implemented by the organization against any perceived additional risk caused by COVID-19.

The hotline was announced through the COVID-19 e-bulletin and the website via the app. The initiative was led by a senior HR executive and supported by experienced administrators from within the HA Head Office. Staff from HA hospitals have the option of calling a dedicated number directly by phone to speak to an administrator, or to send messages through a commonly utilised mobile messaging platform in Hong Kong (WhatsApp) if they so choose, or if they cannot be connected by phone immediately. For enquiries that could not be fully addressed via phone or WhatsApp, the responsible duty officers would relay the enquiries to respective subject officers for an answer and revert back to the caller. The majority of the concerns raised by callers were satisfactorily addressed. This hotline was implemented as management believed that effective and rapid communication during crises helps address staff concerns.

Staff working at high-risk areas are entitled to a "special emergency response allowance" (SERA) which is an additional $20 \%$ of their daily basic salary or at a rate of HK\$500 per day (whichever is higher), as well as "special rental allowance" (SRA) at a fixed rate of HK\$500 per day for renting temporary accommodation if the staff have no occupancy of HA's provided accommodation for residency purpose.

Trust in organizations build on the responsiveness and support offered to staff working in the frontline during a pandemic $(14,15)$. Providing critical hospital services will inevitably require a new norm that takes into consideration long term staff needs, as well as support decision-making on how to resume elective hospital services. It is anticipated that feedback and information gathered through the hotline will guide both immediate and longer-term management planning and staff engagement. Therefore, the aim of this study was to categorise the enquiries from a HCW's staff hotline and to undertake a longitudinal analysis to 
Table 2 Table of categories of enquiries

\begin{tabular}{|c|c|c|c|}
\hline $\begin{array}{l}\text { Major concerns } \\
\text { areas }\end{array}$ & Category & Description & $N(\%)$ of enquiries \\
\hline \multirow[t]{3}{*}{ Infection control } & A. Infection control & $\begin{array}{l}\text { Infection control measures implemented in clinical operations } \\
\text { and standards of PPE provided }\end{array}$ & $255(13.7)$ \\
\hline & $\begin{array}{l}\text { B. Personal protective } \\
\text { equipment (PPE) }\end{array}$ & $\begin{array}{l}\text { Concerns of PPE stockpile and supply for staff and their } \\
\text { family members }\end{array}$ & $136(7.3)$ \\
\hline & D. Facility management & General suggestions to reduce infection risk in common areas & $31(1.7)$ \\
\hline \multirow{3}{*}{$\begin{array}{l}\text { Recognition and } \\
\text { staff wellbeing }\end{array}$} & E. Extra day leave & Extra day-off after working in high-risk areas & $67(3.6)$ \\
\hline & $\begin{array}{l}\text { F. Special rental allowance } \\
\text { (SRA) }\end{array}$ & Information and eligibility of SRA & $385(20.6)$ \\
\hline & H. Accommodation & Provision of free accommodation by Hospital Authority & $58(3.1)$ \\
\hline \multirow[t]{2}{*}{ Duty arrangement } & I. Staff deployment & $\begin{array}{l}\text { Definition of "high-risk" areas, criteria and duration for } \\
\text { deployment to work in "high-risk" areas }\end{array}$ & $109(5.8)$ \\
\hline & J. Quarantine arrangement & $\begin{array}{l}\text { Duty and quarantine arrangements after overseas travel for } \\
\text { staff and family members }\end{array}$ & $248(13.3)$ \\
\hline Others & K. Others & $\begin{array}{l}\text { Includes: industrial action, injury on-duty, psychological } \\
\text { support, etc. }\end{array}$ & $196(10.5)$ \\
\hline Total & & & 1,868 \\
\hline
\end{tabular}

Figures may not add up to $100 \%$ due to rounding. COVID-19, coronavirus disease 2019.

understand the change in the nature of their concerns. The number and types of enquiries would indicate the major areas of staff concerns at all levels, including frontline clinical departments as well as support services.

\section{Methods}

\section{Study design}

A retrospective thematic review and longitudinal analysis of all enquiries by unsolicited phone calls and WhatsApp messages from the staff hotline over the initial 12 weeks of the COVID-19 pandemic in Hong Kong was undertaken, with the intention of identifying the topics and patterns of concern. This will provide health managers with insights on the effects of staff interventions for similar situations in the future.

\section{Data source}

All hotline enquiries received by unsolicited phone calls and WhatsApp messages from staff of the Hong Kong HA during a 12-week period from 29 January, 2020 to 22 April, 2020 were reviewed. Personal identifiers were removed from all enquiries.

\section{Categorisation system}

The review team inductively developed categories based on the type of enquiry. Eleven categories were created. There are overlaps between each category, and the review team agreed that if any enquiry were to suit more than one category, the more specific category would be chosen. Categories of similar themes were also further consolidated into four major concerns areas for high-level analysis (Table 2).

\section{Statistical analysis}

The review team comprised of 3 reviewers, of which 2 were the primary reviewers (AP Mah and KC Tong) and the remaining was the secondary reviewer (LL Chan). The 
Proportion of Healthcare Workers' Concerns

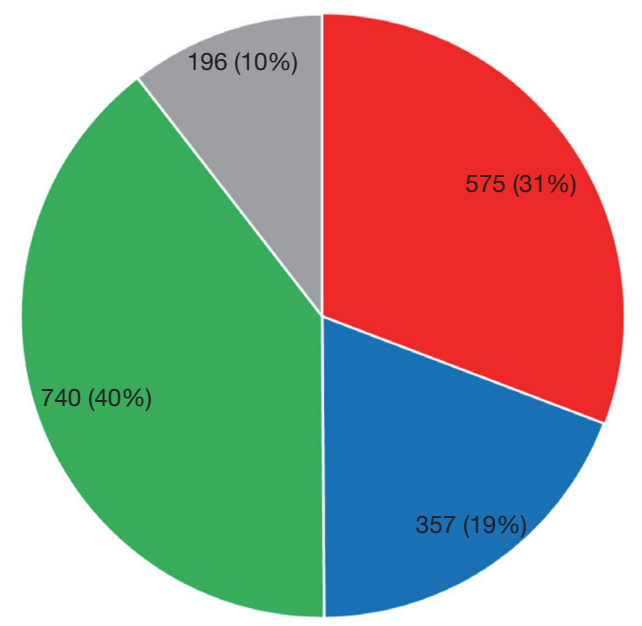

- Infection Control = Duty Arrangement || Recognition \& Staff Wellbeing =Others

Figure 1 Number (\%) of HCW enquiries by major concern areas. $\mathrm{HCW}$, healthcare worker.

primary reviewers first analysed the enquiries independently. The classifications of enquiries were finalised if the two sets of results between the primary reviewers were the same. The level of agreement between primary reviewers was Kappa score $=0.88$, 95\% CI: $0.86-0.99$ and between the primary and secondary reviewer were Kappa scores $=0.91,95 \%$ CI: $0.89-0.93$ and $0.96,95 \%$ CI: $0.95-0.97$. For results that had a discrepancy, the primary reviewers would discuss the results for a consensus. Otherwise, the secondary reviewer would make the final decision on the classification if a mutually agreed decision between the primary reviewers could not be made. A descriptive analysis was then conducted to evaluate the enquiry categories. The numbers and percentages of enquiries were then analyzed by time.

\section{Patient and public involvement}

No patient involved.

\section{Ethics approval and consent to participate}

The study was conducted in accordance with the Declaration of Helsinki (as revised in 2013). The study was approved by Research Ethics Committee of Kowloon
Central Cluster (NO.: KC/KE-20-0123/ER-1) and individual consent for this retrospective analysis was waived.

\section{Results}

Up until 22 April 2020, there were a total of 1,711 instances where staff sought assistance or provided feedback through this hotline and a total of 1,868 enquiries were received. There were calls that crossed more than one enquiry category. The breakdown of enquiries according to categories is shown in Table 2.

In order to further highlight the enquiry categories of HCWs, we were able to group related enquiries into three "major concern areas" (Figure 1): (I) "recognition and staff wellbeing" ( $\mathrm{n}=740,40 \%$ ), which encompass SRA, SERA, extra day-off and free accommodation; (II) "infection control" ( $\mathrm{n}=575,31 \%)$, including general infection control measures, quality and availability of personal protected equipment, staff testing, and facility management suggestions that reduce infection risk in the general work environment, and (III) "duty arrangements" $(\mathrm{n}=357$, $19 \%)$, which includes staff deployment and quarantine arrangement queries. The remainder have been grouped as "others", with 196 enquiries over the whole study period covering a range of topics, including industrial action concerns and requests for psychological support. It is noted that HA has a separate psychological support platform, and thus not all queries relating to this would be captured in this data.

There seems to be no direct correlation between the number of enquiries per day and the number of confirmed COVID-19 cases in Hong Kong (Figure 2). Prior to 18 March, there were a total of 168 confirmed COVID-19 cases, with not more than 15 on any single day, while the majority of hotline enquiries were accounted for during this period. From 18 March, there was a rapid rise in confirmed cases as the Hong Kong government commenced a coordinated effort to repatriate residents back from abroad. However, the number of enquiries continued to decrease and there were no further large spikes of enquiries, with only an increase around 18 March when the government announced on the previous day a 14-day mandatory quarantine period for all persons arriving into Hong Kong, which would affect staff's duty arrangement.

The distribution of call-in and message time suggests that most enquiries were made during the day, but there were still a number of staff who reached out after midnight, predominantly utilising the instant messaging platform 
Enquiry per day vs. confirmed case per day

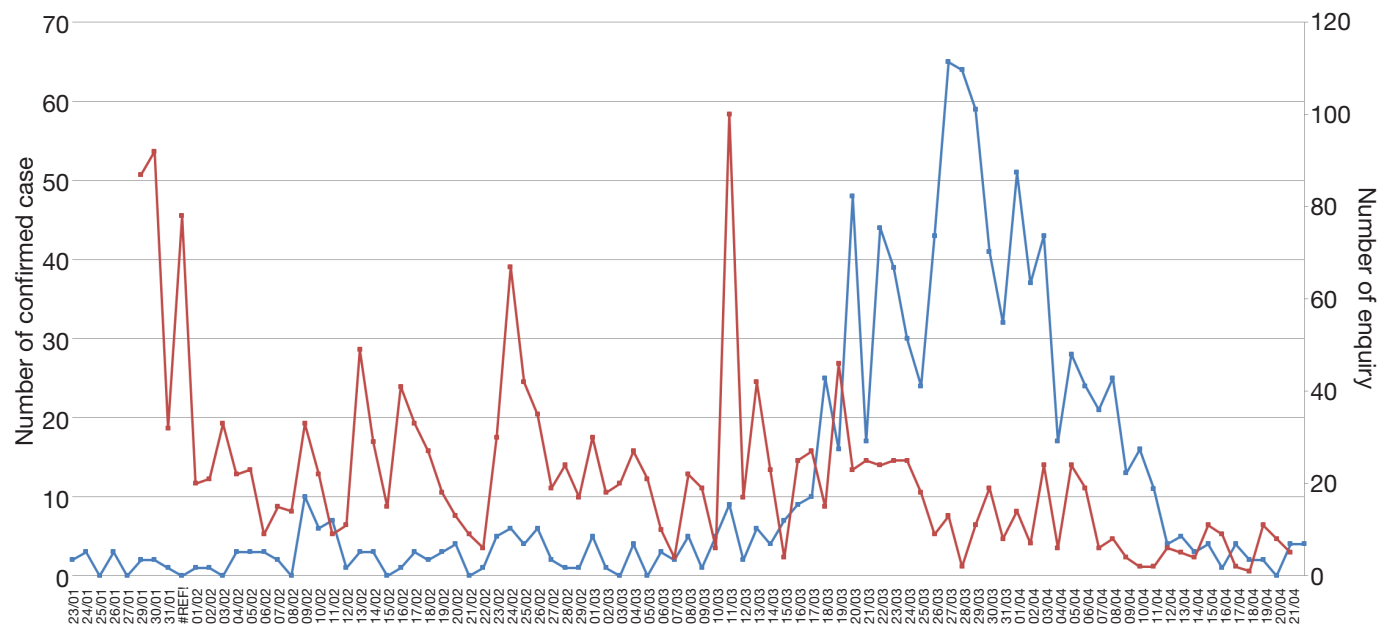

-Confirmed case per day $\quad$-Enquiry per day

Figure 2 Number of enquiries vs. number of new confirmed COVID-19 cases per day. COVID-19, coronavirus disease 2019.

rather than calling by phone (Figure 3). Over two-thirds $(\mathrm{n}=1,273,68 \%)$ of enquiries were raised through WhatsApp Messages which were consistent across the time of day.

Between 29 January to 22 April, 2020, the number of enquiries demonstrated three distinct phases exhibiting high volume of enquiries, likely corresponding to interventions by HA and the government (Figure 4). Before 14 February, the focus seemed to be on "infection control"; between 14 February to 19 March there was a concentration of enquiries on "recognition and staff wellbeing", and between 13 March to 23 March there was a cluster in relation to "duty arrangements" (Figure 4)

In relation to "recognition and staff wellbeing", the majority of calls or messages related to SRA and SERA $(\mathrm{n}=615 / 740,83 \%)$, and occurred after $13^{\text {th }}$ February, which tailed off after 5 weeks, and then peaked on the $24^{\text {th }}$ February. It is noted that before the introduction of the allowance schemes, there was feedback concerning the fairness of drawing lots to determine which staff are to be deployed to high-risk areas (collected under staff deployment/duty arrangements), however, there were no enquiries related to drawing lots since then. In regards to these additional financial recognitions, HCWs enquired about eligibility of allowance, and calculation of payment and payment logistics. Further analysis of major concern area "recognition and staff wellbeing" category, revealed that there was a not insignificant number of enquiries or feedback ( $n=34 / 740,5 \%$ ), that were critical of the application of recognition measures only to selected staff.

\section{Discussion}

This is a thematic review and descriptive analysis of the data collected from the 24-hour hotline set up by the HA for all public hospital staff in Hong Kong in the first 3 months of the COVID-19 pandemic. During this time, there were about 20 measures implemented by HA to address the needs and wellness of staff. Among the hotline queries raised against these measures, the major concern areas of staff can be largely categorized into (I) "infection control", (II) "recognition and staff wellbeing", (III) duty arrangements, and (IV) others. The first three categories account for $90 \%$ of total enquiries.

An observation is the sequence of the three phases of concerns. The initial major concern area was infection control, which included availability of PPE and measures the organization was taking to protect $\mathrm{HCWs}$. As more information became available and HCWs understood the characteristics of the virus and infection control measures, enquiry attention turned to "recognition and staff wellbeing", a significant proportion of which related to financial incentives. Finally, there was a spike in enquiries about "duty arrangements". It is impossible to extrapolate and suggest that all HCWs would react and have concerns 


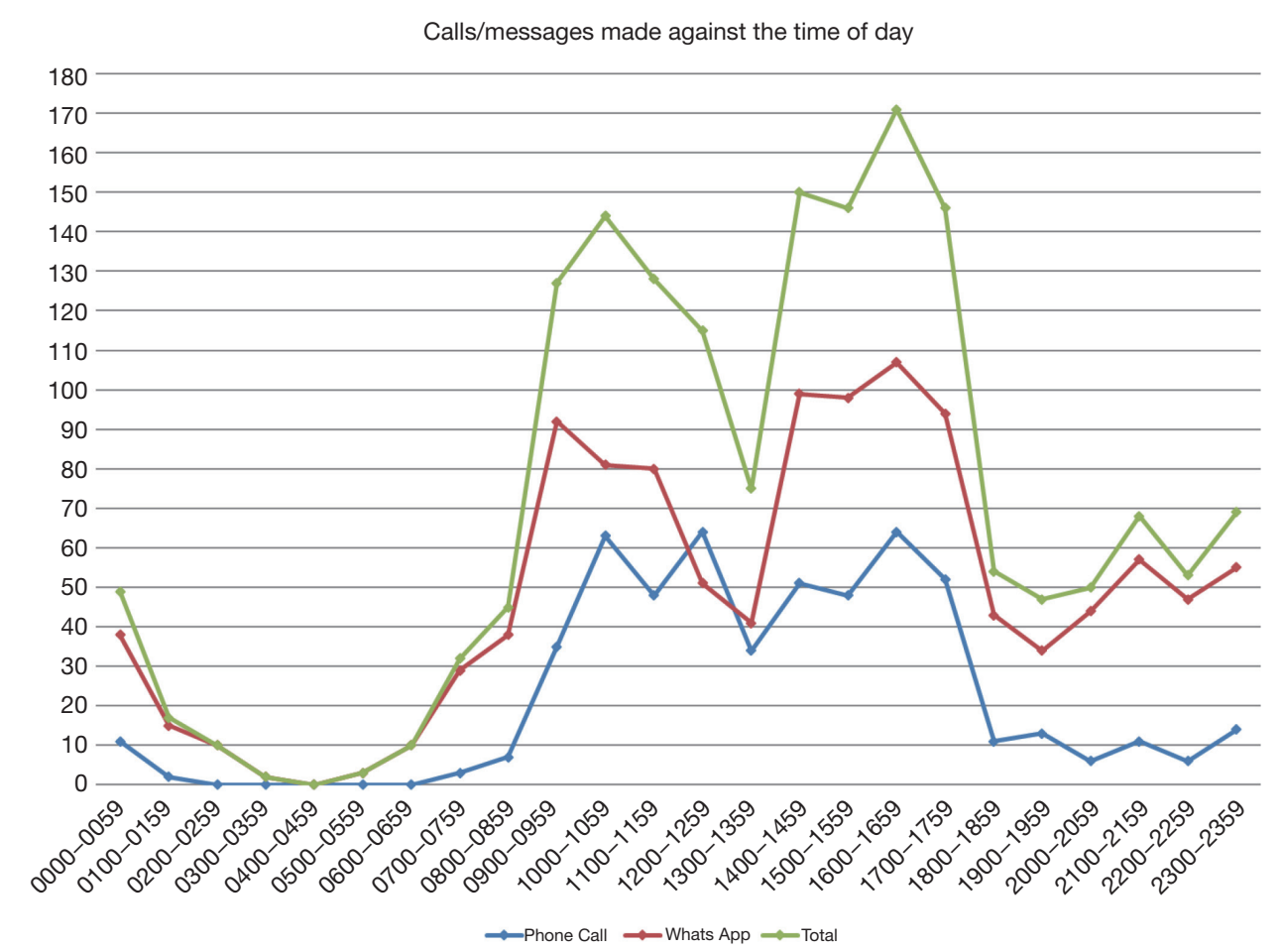

Figure 3 Number of enquiries by time of day and method of contact.

in the same order during pandemics, and the authors believe to a large extent the enquiries might be a reaction to measures adopted by the government and HA. However, suggestions were often raised in staff feedback, which were discussed amongst management, and then implemented. Thus, whether the enquiry types can be a proxy measure for the timing and evolution of $\mathrm{HCW}$ concerns require further study. Regardless, all three aspects must be sufficiently addressed for HCWs over time.

After the first COVID-19 case was confirmed in late January, there was a surge of staff hotline enquiries about PPE. There was no correlation between the daily number of confirmed COVID-19 cases and the corresponding number of HCWs' hotline enquiries. Given that little was known about COVID-19 at this stage, the response is most likely due to uncertainties about the effectiveness and availability of protective measures and unknown infection risk in the workplace. It was not surprising that HCWs had significant concerns in the early stages of COVID-19, as the previous experience from SARS, which has a similar virus group and name, could lead them to regard it as having a high nosocomial infection rate for HCWs (16). Limited information being available from authoritative institutions likely contributed to the high level of concerns initially. The psychological stress is amplified when taking into consideration the need to comply with social distancing measures in the community, and concerns about asymptomatic transmission of the virus to family members living together. The uncertainty was also emotionally toiling during the early stages, as experts predicted that the pandemic could last for a long period of time.

Following the experience from SARS in 2003, HA has maintained a 3-month stockpile of PPE, modeled on a high consumption rate akin to during that outbreak. Through a number of PPE saving measures, cancelling of elective services and outsourcing of services to the private sector, HA was fortunate not to be in a situation where PPE could not be provided to frontline workers treating confirmed or suspected COVID-19 patients. Extra day-off had also been previously drafted into the organisation's HR policy in case of emergency situations, and HA hospitals were able to utilize these established arrangements to flexibly design workplace rosters that take into consideration additional staff workload, stress and infection control measures.

In the past 10 years, HA had enhanced staff communication using the HR App and e-bulletins, to reach staff at an individual level and collect feedback electronically simply by accessing the quick response (QR)-code on the 


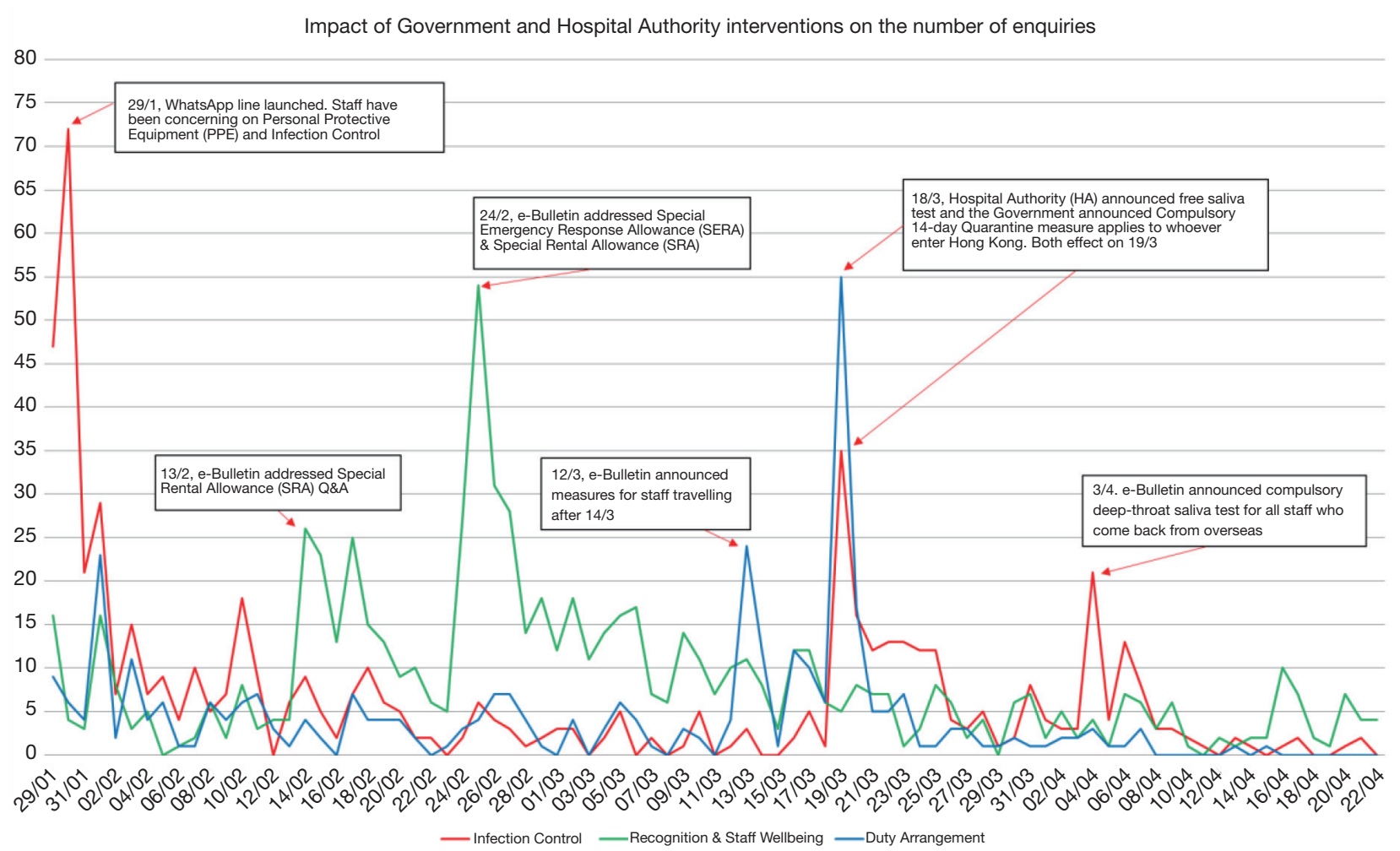

Figure 4 Number and type of calls per day in relation to government and organization interventions.

bulletin. These platforms allow rapid dissemination of information and direct feedback from staff via their mobile phones or other electronic devices to senior management. By pushing COVID-19 related information to HCWs via HR App and providing updated information and data on the dedicated website, fear and stress of HCWs were likely eased through better knowledge and understanding, in particular regarding the effectiveness and availability of PPE. As demonstrated by the hotline data, around a week after communication on a highlighted topic, related enquiries drop quickly. This observation is consistent with other hotline enquiries pertaining to PPE, staff deployment, leave arrangements and free saliva testing for staff. This is also in line with literature that suggest effective and rapid communication during crises helps address staff concerns (5).

HCWs were concerned about having accommodation provided by the hospitals $(\mathrm{n}=39 / 58,67 \%$ of all accommodation enquiries), in order to protect their family members from infection. The limited number of hospital-maintained quarters simply could not cater for the number of staff who might be at risk. With a major health workforce shortage already placing significant burdens on the public sector (17), the hospitals also found it difficult to arrange sufficient manpower to cover usual hospital operations due to increasing number of confirmed cases admitted to isolation facilities. As a result, HA developed two financial incentives to recognize staff who were willing to work in high-risk areas, being SRA and SERA. With the announcement of the special allowances, there was a sustained surge of enquiries over a 6 -week period, mainly regarding the staff member's eligibility for the allowance and payment logistics. It is noted that after the implementation of SRA and SERA, hospitals received less enquiries about the provision of accommodation and scheduling of HCWs to work in high-risk areas.

However, it is debatable whether an organization should use financial incentives to improve HCW morale or to encourage working in high-risk areas during a pandemic. From a healthcare organization's perspective, the management team has a responsibility to allocate sufficient manpower to maintain services, however, as demonstrated previously, HCWs may not be willing to be deployed to high-risk areas during a pandemic $(4,7,8)$ The recognition provisions by HA were created to sustain critical services, 
as well as to provide relief by way of additional leave days for HCWs who will require rest after a prolonged period of work in high-risk areas. Providing financial rewards as a tactic for sustaining attendance has been previously utilized, notably in Toronto during the SARS epidemic, however study and discussion on this area has remained scarce (18). Individually, some HCWs may not agree with the use of financial incentives in these situations, which may challenge one's innate feeling of professionalism, or the rational argument that for caring patients under such circumstances are part of normal duty and contractual obligations (18). It has previously been shown that HCWs believe that during an epidemic crisis, leadership, team camaraderie and a shared value of duty was considered more important rather than financial rewards $(6,19)$. It is also the common goal of professionals and healthcare organization to have a safe workplace to deliver quality care to patients. HCWs' attitudes towards financial incentives should be explored, and benefits and disadvantages of implementing such measures better understood, as it will help guide a management team in formulating strategies to ensure a sufficient and sustainable workforce during a pandemic.

While maintaining the morale of front-line workers during pandemic is of paramount importance, hospital managers should assess the longer-term implication and possible negative impacts of financial incentives. The implementation of financial incentives surfaced at least two challenges that health managers need to consider in future.

Firstly, since financial incentives were implemented, there were queries about why certain staff functions and duties were not considered "high risk". This could lead to workplace concerns about fairness and equity and could lead to division across healthcare teams or differentiation of work in hospitals by perceived importance. Secondly, it creates a precedence and raises questions as to when special financial incentives should be provided in the future. In particular, where to draw the threshold for applying financial incentives will be difficult to be defined. One option is to link the decision to the WHO's declaration of a Public Health Emergency of International Concern (PHEIC), the process which is outlined in the International Health Regulations (20). For situations like COVID-19 where the epidemic lasts for an extended period of time, it is uncertain whether professionalism and camaraderie is sufficient to maintain morale, and whether additional incentives might be required.

The response of HCWs towards the pandemic will be affected by substantial confounding factors that might not be identified such as the culture and the trust in the organization and government. However, this is the first review of HCWs' concerns over 3-month pandemic with financial incentives. It captures real time HCW's queries, instead of prospective or retrospective feedback data collected by questionnaires.

\section{Conclusions}

This study provided an insight into what HCW were concerned about in the healthcare organization. The three major concerns areas for the staff were around infection control, recognition and staff welling, and duty arrangements, in that sequence. However, the timing of the concern areas may be in response to government or organisation interventions. Unsurprisingly staff were initially concerned about infection control measures such as the provision of appropriate PPE and availability of COVID-19 tests. The organisation rolled out financial incentives to prevent workforce shortages in critical service areas, and while this objective was seemingly achieved, there might have been certain drawbacks that might not have been taken into account early on. These include setting precedence for additional financial compensation to staff during future crisis situations, division amongst staff due to eligibility, and potentially challenging the professionalism of clinicians. The authors suggest that further studies be conducted into the use of financial incentives to retain staff during crisis situations, to understand the benefits and detriments of this approach. Our findings confirm previous studies that staff concerns can be alleviated by effective communication channels.

\section{Acknowledgments}

The authors would like to thank all the staff who maintained the 24-hour hotline, for listening to and resolving staff concerns, and documenting crucial information so that this review could be performed. Appreciation also goes to Professor Jeffrey Braithwaite for his advice during the final stages of drafting.

Funding: None.

\section{Footnote}

Reporting Checklist: The authors have completed the MDAR reporting checklist and STROBE reporting checklist. Available at http://dx.doi.org/10.21037/jhmhp-20-142 
Data Sharing Statement: Available at http://dx.doi. org/10.21037/jhmhp-20-142

Conflicts of Interest: All authors have completed the ICMJE uniform disclosure form (available at http://dx.doi. org/10.21037/jhmhp-20-142). The authors have no conflicts of interest to declare.

Ethical Statement: The authors are accountable for all aspects of the work in ensuring that questions related to the accuracy or integrity of any part of the work are appropriately investigated and resolved. The study was conducted in accordance with the Declaration of Helsinki (as revised in 2013). The study was approved by Research Ethics Committee of Kowloon Central Cluster (No. $\mathrm{KC} / \mathrm{KE}-20-0123 / \mathrm{ER}-1$ ) and individual consent for this retrospective analysis was waived.

Open Access Statement: This is an Open Access article distributed in accordance with the Creative Commons Attribution-NonCommercial-NoDerivs 4.0 International License (CC BY-NC-ND 4.0), which permits the noncommercial replication and distribution of the article with the strict proviso that no changes or edits are made and the original work is properly cited (including links to both the formal publication through the relevant DOI and the license). See: https://creativecommons.org/licenses/by-nc-nd/4.0/.

\section{References}

1. World Health Organisation 2020, "Coronavirus disease (COVID-2019) situation reports." Situation Report 5161. Available online: https://www.who.int/emergencies/ diseases/novel-coronavirus-2019/situation-reports (accessed 3 July 2020)

2. The Government of the Hong Kong Special Administration Region Press Release 2020, "LCQ21: Using Chinese medicine to prevent and treat Coronavirus Disease 2019”, 22 April 2020. Available online: https://www.info.gov.hk/gia/general/202004/22/ P2020042200274.htm (accessed 3 July 2020)

3. The Government of the Hong Kong Special Administration Region 2020, "Patient discharge criteria explained”, 12 February 2020. Available online: https:// www.news.gov.hk/eng/2020/02/20200212/20200212_1800 53_610.html?type=ticker (accessed 3 July 2020)

4. Ehrenstein BP, Hanses F, Salzberger B. Influenza pandemic and professional duty: family or patients first? A survey of hospital employees. BMC Public Health 2006;6:311.

5. Shanafelt T, Ripp J, Trockel M. Understanding and Addressing Sources of Anxiety Among Health Care Professionals During the COVID-19 Pandemic. JAMA 2020;323:2133-4.

6. Lee SH, Juang YY, Su YJ, et al. Facing SARS: psychological impacts on SARS team nurses and psychiatric services in a Taiwan general hospital. Gen Hosp Psychiatry 2005;27:352-8.

7. Qureshi K, Gershon RR, Sherman MF, et al. Health care workers' ability and willingness to report to duty during catastrophic disasters. J Urban Health 2005;82:378-88.

8. Balicer RD, Omer SB, Barnett DJ, et al. Local public health workers' perceptions toward responding to an influenza pandemic. BMC Public Health 2006;6:99.

9. He X, Lau EHY, Wu P, et al. Temporal dynamics in viral shedding and transmissibility of COVID-19. Nat Med 2020;26:672-5. Erratum in: Nat Med. 2020 Sep;26(9):1491-1493. doi: 10.1038/s41591-020-1016-z.

10. Cowling BJ, Ali ST, Ng TWY, et al. Impact assessment of non-pharmaceutical interventions against coronavirus disease 2019 and influenza in Hong Kong: an observational study. Lancet Public Health 2020;5:e279-88.

11. Lum A. Coronavirus epidemic will not end this year, Hong Kong's leading microbiologist says. South China Morning Post 2020, 8 March. Available online: https:// www.scmp.com/news/hong-kong/health-environment/ article/3074127/coronavirus-epidemic-will-not-end-yearhong-kongs (accessed 3 July 2020)

12. Grasselli G, Pesenti A, Cecconi M. Critical Care Utilization for the COVID-19 Outbreak in Lombardy, Italy: Early Experience and Forecast During an Emergency Response. JAMA 2020;323:1545-6.

13. British Psychological Society Covid19 Staff Wellbeing Group. The Psychological Needs of Healthcare Staff as a Result of the Coronavirus Pandemic. Leicester: The British Psychological Society 2020. Available online: https://www.bps.org.uk/sites/www.bps.org.uk/files/News/ News\%20-\%20Files/Psychological\%20needs\%20of\%20 healthcare\% 20staff.pdf (accessed 3 July 2020)

14. Frewer L. Environmental risk, public trust and perceived exclusion from risk management. In: Böm G, Nerb J, McDaniels T, et al. editors. Environmental risks: perception, evaluation and management. Research in Social Problems and Public Policy, Vol. 9, Emerald Group Publishing Limited, Bingley, 2001:221-48.

15. Edelman, Edelman Trust Barometer 2020 Special Report: Trust and the Coronavirus" 2020, Available 
online: https://www.edelman.com/sites/g/files/aatuss191/ files/2020-03/2020\%20Edelman\%20Trust\%20

Barometer\%20Coronavirus\%20Special\%20Report_0.pdf (accessed 3 July 2020)

16. Lau JT, Yang X, Leung PC, et al. SARS in three categories of hospital workers, Hong Kong. Emerg Infect Dis 2004;10:1399-404.

17. Our Hong Kong Foundation 2019. Health System Capacity Constraints-The Severe Shortage of Doctors in Hong Kong Public Hospitals. Available online: https:// www.ourhkfoundation.org.hk/sites/default/files/media/ pdf/ManpowerPPT_20190410_full_eng.pdf (accessed 3 July 2020)

doi: 10.21037/jhmhp-20-142

Cite this article as: Mah AP, Tong KC, Chan LL, Hibbert PD, Pang FC. Hong Kong healthcare workers' coronavirus disease 2019 (COVID-19) concerns: infection control, recognition and staff wellbeing, duty arrangements. J Hosp Manag Health Policy 2021;5:38.
18. Simonds AK, Sokol DK. Lives on the line? Ethics and practicalities of duty of care in pandemics and disasters. Eur Respir J 2009;34:303-9.

19. Khalid I, Khalid TJ, Qabajah MR, et al. Healthcare Workers Emotions, Perceived Stressors and Coping Strategies During a MERS-CoV Outbreak. Clin Med Res 2016;14:7-14.

20. World Health Organisation 2016. International Health Regulations (2005). 3rd Edition. Available online: https://apps.who.int/iris/bitstream/hand le/10665/246107/9789241580496-eng.pdf;jsessionid=2 C64BD3354CAF04B95701E980407CC40? sequence $=1$ (accessed 3 July 2020) 